\title{
Carotid Angioplasty and Stenting for Atherosclerotic Stenosis: Case Series
}

\author{
FAROUK HASSAN, M.D. \\ The Department of Radiology, Faculty of Medicine, Cairo University
}

\begin{abstract}
Background: Carotid artery stenting is an alternative to endarterectomy in treatment of carotid artery stenosis. Comparative studies have shown different results regarding the outcome of both techniques.
\end{abstract}

Aim of Study: The aim of our study is to present our experience in carotid artery stenting and compare our results with the literature.

Patients and Methods: A retrospective analysis of our series of patients who underwent carotid artery angioplasty/ stenting, between January 2011 and April 2018, in Kasr AlAiny University Hospital and Sheikh Zayed Specialized Hospital was performed. Peri-procedural and delayed, minor and major complications rates as well as the rate of restenosis over the follow-up period were analyzed.

Results: A total of 106 patients who underwent 109 procedures of carotid artery angioplasty/stenting were included for analysis. Average age of patients was $63 \pm 7$ years, with 71 male $(67 \%)$. Symptomatic stenosis was seen in 81 cases $(74.3 \%)$ and asymptomatic stenosis was seen in 28 cases $(25.7 \%)$. Filter protection device was used in 69 cases $(63.3 \%)$ and 40 cases $(36.7 \%)$ were done without protective device. Pre-stent dilatation was performed in 21 cases $(19.2 \%)$. Poststent dilatation was performed in 75 cases $(68.8 \%)$. Both pre and post-stent dilatations were done in 9 cases $(8.2 \%)$. No balloon dilatation was done in 3 cases $(2.7 \%)$. In one case $(0.9 \%)$ angioplasty was done without stenting. Minor complications occurred in 4 cases $(3.7 \%)$ in the form of 3 cases of intra-procedural and 1 case of post-procedural transient ischemic attack. Two major complications $(1.8 \%)$ occurred in the form of distal showering with middle cerebral artery occlusion in 1 case, and retroperitoneal hematoma in another case. Two cases $(1.8 \%)$ of intraprocedural adverse events occurred in the form of dissection without clinical sequelae. Two cases of insignificant restenosis were encountered in the follow-up.

Conclusion: Carotid artery stenting is an effective and relatively safe alternative to carotid endarterectomy. Further studies assessing the value of embolic protective devices and the best type of stent should be conducted.

Key Words: Angioplasty - Stenting - Carotid stenosis.

Correspondence to: Dr. Farouk Hassan, The Department of Radiology, Faculty of Medicine, Cairo University

\section{Introduction}

CEREBROVASCULAR stroke is the third cause of death and the first cause of permanent disability [1]. According to the population-based study of the Northern Manhattan Stroke Study, atherosclerosis of the extracranial arteries was the cause of ischemic stroke in 5\% of white patients, $9 \%$ of Hispanic patients, and $17 \%$ of black patients [2]. The randomized controlled trials published in the 1980s and 1990s showed the benefit of Carotid Endarterectomy (CEA) compared to medical treatment in prevention of stroke in patients with moderate and severe symptomatic carotid stenosis [3,4]. In August 2004, the U.S. Food and Drug Administration (FDA) approved the first carotid artery stenting system. Over the years the technology of the materials used has evolved significantly $[\boldsymbol{r}$. The American guidelines considered the carotid artery stenting an alternative to carotid endarterectomy with level of evidence B for patients indicated for carotid artery revascularization [6]. Despite the number of studies published in the literature regarding the validation of the carotid artery stenting, many contradictory results are still found. This led to a discrepancy in the protocols of management in different countries according to the level of experience available and their different results.

\section{Material and Methods}

A cross-sectional study of our series of patients who underwent internal carotid artery angioplasty/ stenting between January 2011 and December 2018 in Kasr Al-Ainy University Hospital and Sheikh Zayed Specialized Hospital, was performed.

The institutional review board of our Radiology Department approved the design of the study and the use of clinical data.

Patients were referred from the Neurology or the Cardiology Departments to our Interventional Radiology Unit for carotid angioplasty/stenting. 
Inclusion criteria involved patients with $\geq 50 \%$ symptomatic stenosis or $\geq 70 \%$ asymptomatic stenosis of the extracranial carotid according to "North American Symptomatic Carotid Endarterectomy Trial" (NASCET) measurements. The degree of stenosis was measured in all cases before treatment depending on a good quality CT angiography. Pretreatment MRI was done in all cases to evaluate the viability of the brain tissue of the territory supplied by the stenotic artery to be treated. The lesion was considered symptomatic if the patient suffered from a corresponding cerebrovascular stroke or TIA in the last 6 months or in case of recent ischemic lesion seen in the diffusion weighted images even if it was subclinical. All patients were given the choice to perform angioplasty/ stenting or endarterectomy.

We excluded patients with heavily calcified circumferential plaques, patients with type III aortic arch and markedly tortuous carotid artery and patients with high renal function tests after nephrology consultation. Those patients were referred for endarterectomy.

Full neurological assessment of the patients was performed before the procedure.

Written informed consent was obtained from all patients before treatment.

Patients were prepared by double antiplatelet (Aspirin 150mg and Plavix 75mg daily) for 5-7 days before treatment.

All patients were treated under local anaesthesia. Right arterial femoral puncture was done using Seldinger technique, followed by introduction of 8 French femoral sheath. Diagnostic digital subtraction angiography of both carotid arteries was done routinely to confirm the exact degree of stenosis, to assess the intracranial circulation and the collateral pathways.

Guiding catheter 8 French (Guider soft tip, Boston scientific, USA) was then introduced into the common carotid artery.

Loading dose of heparin $(70 \mathrm{IU} / \mathrm{Kg})$ was administered just after introduction of the guiding catheter to the carotid artery.

The need to use filter protection device was decided according to the type of plaque, the angulation of the artery determining the easiness of filter navigation and the availability of the filter. In case of no filter use, navigation was done using Transend soft tip 0.014" microguidewire (Boston scientific, USA).
The need for pre-stent dilatation was determined according to the degree of stenosis.

The type of stent used was Wallstent (Boston scientific, USA) in 85 cases, Protégé (Medtronic, USA) in 22 cases and Roadsaver (Terumo Corp, Tokyo, Japan) in 1 case. Software calibration and measurement of the artery was done to determine the length and diameter of the stent needed.

Balloon angioplasty and deployment of the stent was done under roadmap control.

The need for post-stent dilatation was determined according to the residual degree of stenosis after the stent deployment.

Pre and post-stent dilatation was done using Sterling balloon (Boston scientific, USA) of different calibers.

The vital signs of the patients were monitored throughout the whole procedure.

Atropine was administered in case of bradycardia during balloon angioplasty.

In case of tight stenosis or heavily calcified plaque we were satisfied by submaximal dilatation of the stenotic lesion.

Control digital subtraction angiography was done at the end of the procedure to assess the treated cervical segment of the carotid artery and the patency of its intracranial branches.

Femoral sheath was then removed followed by manual compression of the puncture site.

Strict monitoring of the blood pressure of the patient was then performed for 48 hours.

The patients were kept under double antiplatelet therapy for 3 months, followed by single antiplatelet for life.

Neurological assessment of the patients was done in the first 48 hours, after 1 week, after 1 month and after 1 year from the procedure.

Follow-up carotid duplex was done after 1 year.

\section{Results}

A total of 106 patients were treated, in 109 sessions of carotid artery angioplasty/stenting, as 3 patients had bilateral carotid stenoses that were treated with 3 months gap between both sessions.

Age of patients was $63 \pm 7$ years, with a mean age of 65 . 

(33\%).

Patients were 71 male (67\%) and 35 female

Symptomatic stenosis was seen in 81 cases $(74.3 \%)$ and asymptomatic stenosis was seen in 28 cases $(25.7 \%)$.

In 69 cases $(63.3 \%)$ filter protection device was used and 40 cases (3 6.7\%) were done without protective device.

Pre-stent dilatation was needed in 21 cases (19.2\%). Post-stent dilatation was performed in 75 cases $(68.8 \%)$. Both pre and post-stent dilatations were done in 9 cases $(8.2 \%)$. In 3 cases $(2.7 \%)$ no balloon dilatation was done and in one case $(0.9 \%)$ angioplasty was performed without stenting.

Minor complications occurred in 4 cases (3.7\%): 2 cases suffered from intra-procedural transient ischemic attack that resolved during the procedure. One case suffered from post-procedural Transient
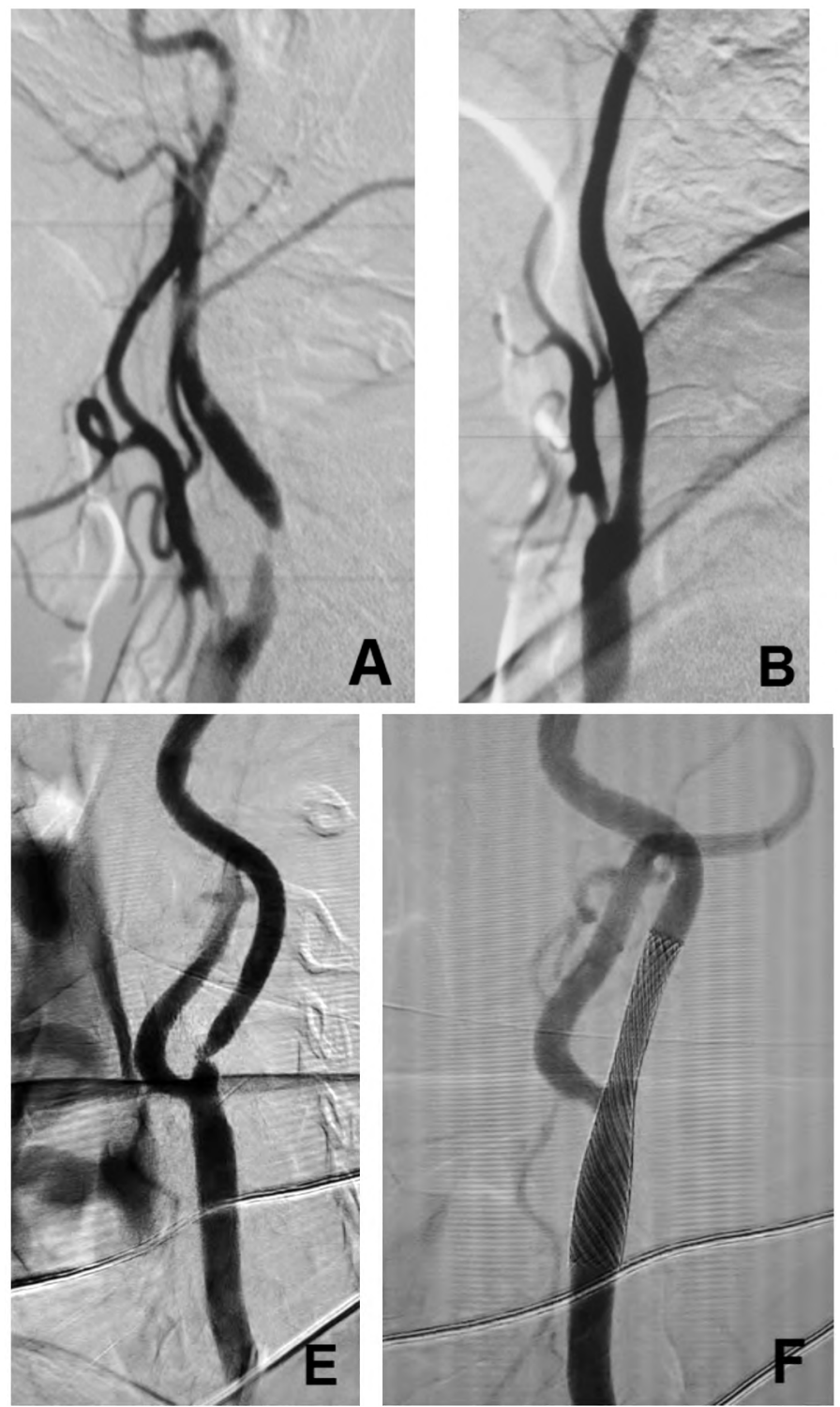

Ischemic Attack (TIA) that resolved completely after 35 minutes. In one case dissection of the ulcerated plaque occurred during the microguidewire navigation which necessitated 40 minutes to recanalize the artery. General anaesthesia was induced during that time as the patient lost his consciousness. After the procedure the patient was clinically intact.
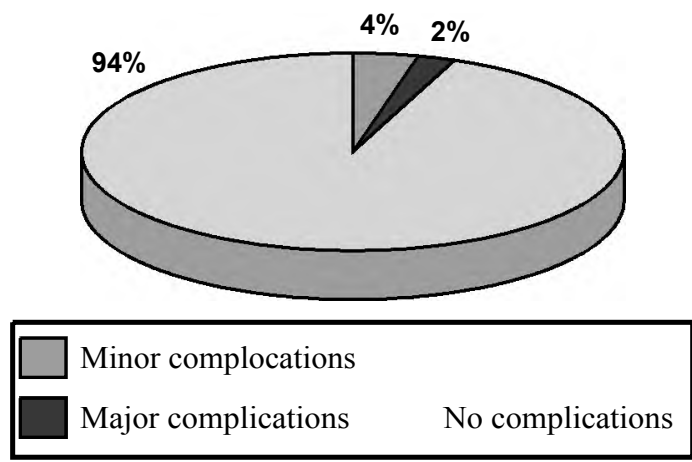

Chart (1): Periprocedural complications rate.
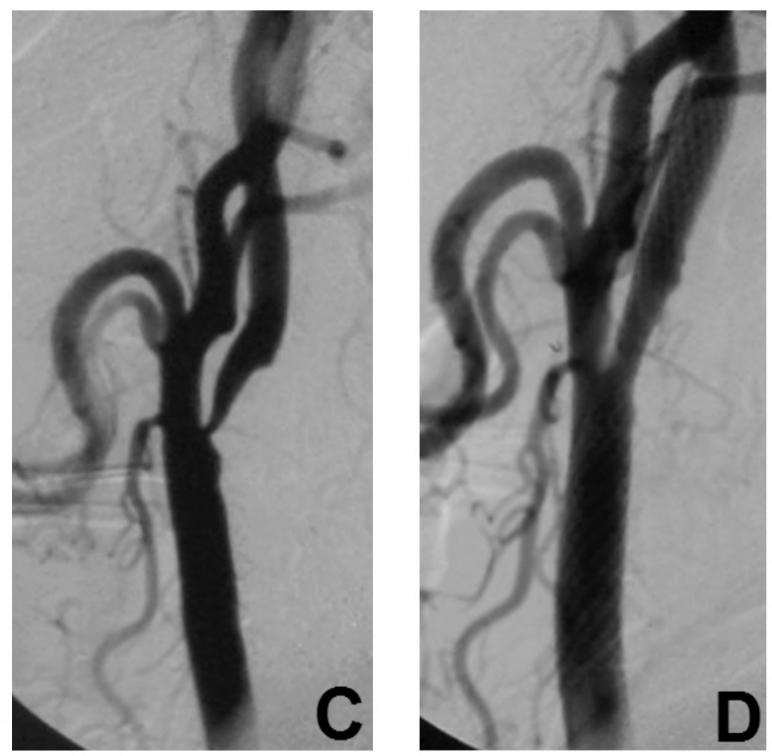

Fig. (1): Digital subtraction angiography for stenotic lesions of the internal carotid artery, before and after angioplasty/stenting. (A, B) Female patient 59 years old, presenting by left parietal infarction. (C, D) Male patient 61 years old, presenting by recurrent right side attacks of transient ischemic attacks. (E, F) Male patient 63 years old, presenting by left parietal infarction.

a- Post-bulbar $95 \%$ stenosis before angioplasty/stenting.

b- Well deployed Wallstent with adequate dilatation of the stenotic lesion.

c- Carotid bulb stenosis estimated to $90 \%$ before angioplasty/stenting.

d- Well deployed Wallstent with adequate dilatation of the stenotic lesion.

e- Carotid bulb stenosis estimated to $70 \%$ before angioplasty/stenting.

f- Well deployed Wallstent with adequate dilatation of the stenotic lesion. The artery is straightened by the relatively rigid Wallstent. 
Two major complications (1.8\%) occurred. In one patient an embolus showered from the carotid plaque during a pre-stent dilatation and occluded the M 1 segment of the middle cerebral artery. Immediate mechanical thrombectomy was done and retrieval of the embolus was achieved. However the patient suffered from post-procedural hemiplegia grade 2 and was Modified Rankin scale (mRs) 3 at 3 months follow-up. One patient suffered from massive retroperitoneal hematoma the night of the procedure that necessitated surgical intervention.

In 2 cases (1.8\%) intraprocedural adverse events occurred. In one case minimal dissection occurred, didn't necessitate further management and no clinical sequelae occurred. In one case dissection of the ulcerated plaque occluded the artery completely for 40 minutes but the patient was clinically free after the procedure.

Forty four patients $(41.5 \%)$ presented to the clinic for follow-up after 1 year. The rest of patients didn't show up.

Two cases $(4.5 \%)$ among the 44 patients who presented for follow-up after 1 year had hemodynamically insignificant and asymptomatic restenosis
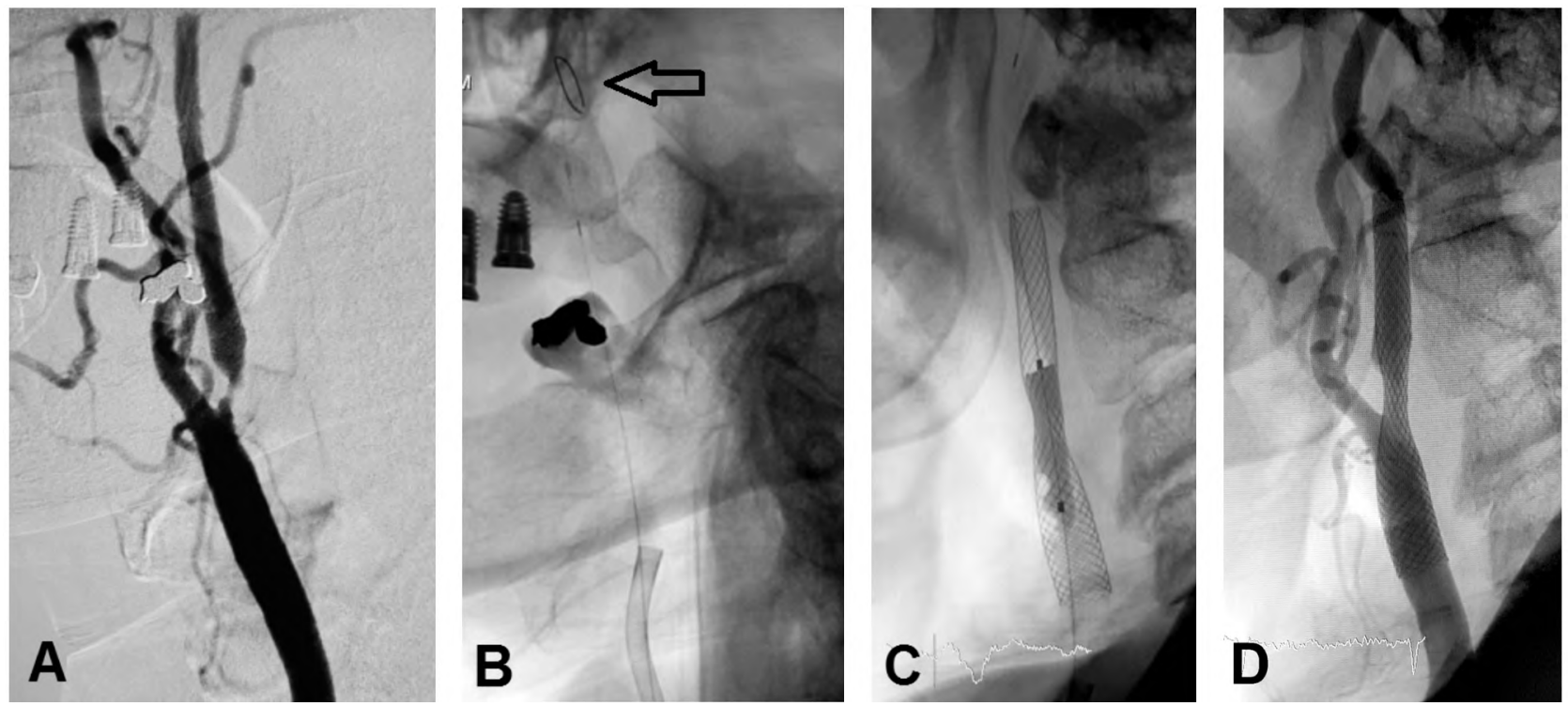

Fig. (3): Angioplasty/stenting of right carotid bulb stenosis, for 67 years old male patient presenting by right cerebral infarction. a- Digital subtraction angiography showing short focal segment of carotid bulb $90 \%$ stenosis before angioplasty/stenting. b- Non-subtracted image showing filter protection device (arrow) opened before angioplasty/stenting. c- Non-subtracted image showing balloon angioplasty after Wallstent deployment.

d- Non-subtracted angiography showing adequately opened stent after balloon angioplasty.

\section{Discussion}

Extracranial atherosclerotic stenosis was reported to be responsible about $10-15 \%$ of all strokes [7]

The "European Carotid Surgery Trial" (ECST) in 1998 showed better clinical outcome with en- darterectomy compared to medical treatment for patients with symptomatic severe carotid stenosis [4]

Same conclusion was reached through the "North American Symptomatic Carotid Endarterectomy" (NASCET) Trial published in 1999. In 
patients with severe symptomatic stenosis ( $>70 \%)$, the endarterectomy had $9 \%$ risk of ipsilateral stroke after 2 years, compared to $26 \%$ with medical treatment. In patients with moderate symptomatic stenosis $(50 \%-69 \%)$, surgery reduced the risk of ipsilateral stroke from $22.2 \%$ to $15.7 \%$ after 5 years [3]

In 2004 the "Stenting and Angioplasty with Protection in Patients at High Risk for Endarterectomy" (SAPHIRE) trial showed lower complication rate with stenting compared to endarterectomy in patients with high surgical risk [8].

Many controlled trials were then conducted, randomizing patients eligible for both stenting and endarterectomy.

In 2006, the "Stent-Protected Angioplasty versus Carotid Endarterectomy" (SPACE) trial failed to show non-inferiority of stenting compared to endarterectomy concerning the peri-procedural complication rate [9].

The "Endarterectomy versus Angioplasty in Patients with Symptomatic Severe Carotid Stenosis" (EVA-3S) trial was stopped prematurely for safety reasons. The 30-day stroke or death rate was significantly higher in the stenting group $(9.6 \%)$ than in the endarterectomy group $(3.9 \%)$ [10].

The "International Carotid Stenting Study" (ICSS) enrolled in 50 centers worldwide and published in 2010, showed higher complication rate with stenting (8.5\%) compared to surgery (5.2\%); considering stroke, myocardial infarction, or death within 120 days of randomization [11]. However the long-term results of ICSS trial showed that the number of fatal or disabling strokes and cumulative 5 -year risk was almost similar between the stenting and endarterectomy groups (6.4\% versus $6.5 \%)$. The functional outcome measured by the modified Rankin scale at 1 year and 5 years didn't differ significantly [12]

The "North American Carotid revascularization Endarterectomy versus Stenting Trial" (CREST) showed discrepancies in the peri-procedural complication rate between the stenting group and the endarterectomy group: Rate of death and stroke was higher with stenting compared to endarterectomy $(0.7 \%$ versus $0.3 \%)$ and $(4.1 \%$ versus $2.3 \%)$ respectively. Whereas peri-procedural myocardial infarction was more frequent with endarterectomy compared to stenting (2.3\% versus $1.1 \%)$. Whilst after the initial period, the rate of stroke was similar in both groups (2.0\% versus $2.4 \%$ ) up to 4 years [13]. The 10-year follow-up of CREST trial was published in 2016 and showed no significant difference in the rate of the primary composite end point (stroke, myocardial infarction or death) between the stenting group (11.8\%) and the endarterectomy group (9.9\%) [14]

A systematic review of the Cochrane Database was published in 2012 for randomized trials of stenting versus endarterectomy for patients at standard surgical risk. It included 5778 patients from 11 randomized trials. It found increased risk of procedural stroke or death with stenting $(8.2 \%)$ compared with endarterectomy $(5.0 \%)$. However, the rate of myocardial infarction, cranial nerve palsy and local site hematoma were higher with endarterectomy compared with stenting $(1 \%, 5.5 \%$ and $2.7 \%$ compared with $0.4 \%, 0.3 \%$ and $0.9 \%$ respectively) [15].

A meta-analysis for the short-term outcome in 3 trials (EVA-3S, SPACE and ICSS) showed that the difference in periprocedural risks between stenting and endarterectomy was caused by a higher incidence of minor strokes in the stenting group, but no significant difference was found regarding the disabling stroke or death. Age was also found to be a main factor. Above 70 years old, the primary outcome event occurred in $12 \%$ of the stenting group compared with $5.9 \%$ in the endarterectomy group. Whereas below 70 years old there were no difference between the rate of complication in both groups $(5.8 \%$ versus $5.7 \%)$ [16]. This age-related discrepancy was confirmed in another more recent meta-analysis studying patients older than 80 years old [17]

A preplanned pooled analysis of individual patient data for the 4 largest randomised controlled trials of stenting and endarterectomy showed that both treatments had similar outcomes in the postprocedural period. The annual rates of ipsilateral stroke per person-year were $0.60 \%$ with stenting and $0.64 \%$ with endarterectomy, indicating similar clinical durability for both approaches [18]

The American guidelines consider the carotid artery stenting an alternative to carotid endarterectomy with level of evidence B for patients indicated for carotid artery revascularization, and state that patients should have the choice [6]

In our study periprocedural ischemic event occurred in 5 cases $(4.6 \%)$. Four cases had transient ischemic attack during or just after the procedure. Whereas, major stroke occurred in just one case $(0.9 \%)$. This result corresponds with the rand- 
omized trials showing that most complications were related to minor non-disabling stroke. The overall low complication rate in our study was probably related to our trend to avoid treating patients older than 70 years old, which was proved from the literature to be related to the complication rate of stenting [16].

On the other hand no patients suffered from peri-procedural myocardial infarction or cranial nerve palsy in our study. Whereas local site hematoma occurred in 1 case $(0.9 \%)$ and resulted into severe retroperitoneal hematoma that necessitated surgical evacuation.

Patients with asymptomatic stenosis are treated differently; in USA, $90 \%$ of stenting are performed for asymptomatic patients. While in Denmark all patients with asymptomatic stenosis are treated medically $[\mathbf{1 9 , 2 0 ]}$. The "Asymptomatic Carotid Atherosclerosis Study" (ACAS) and the "Asymptomatic Carotid Surgery Trial" (ACST) were 2 large multicenteric trials which showed that carotid endarterectomy was better than medical treatment for patients with asymptomatic severe carotid stenosis [21,22]. The "Asymptomatic Carotid Trial" (ACT I) showed that stenting was non-inferior to endarterectomy for patients with asymptomatic severe carotid stenosis [23]. However, since 2002, medical management improved with the intensive medical therapy including statins, antiplatelets and strict risk factors control. Studies showed that the risk of stroke was consequently reduced to a level which may be less than the risk of revascularization [24]. CREST 2 trial is an ongoing multicenteric randomized controlled trial comparing stenting to endarterectomy and to intensive medical therapy, for patients with asymptomatic severe carotid stenosis. The study is still recruiting patients with estimated completion date in December 2020. It is expected to identify the controversial best approach of treatment for asymptomatic patient with carotid stenosis [25]. In our study, we were including patients with $>$ _ $70 \%$ asymptomatic stenosis.

In our study the intra-procedural ischemic events occurred in 4 cases $(3.7 \%)$. In one case it was related to intraprocedural dissection, whereas it was probably related to showering of emboli in the 3 other cases. In 2 cases these emboli were microemboli that didn't induce any large vessel occlusion, but resulted into a TIA and resolved rapidly during the procedure. One of these 2 cases was done under filter protection device, whilst in the other case no filter was used. The sizeable embolus that showered and occluded the MCA and necessitated mechanical thrombectomy was done under protection of filter. These results correspond to the debatable efficacy of the protection device in the literature [5]. There is a need to plan randomized controlled trials for stenting with or without protection device.

In our study the types of stents used were mainly Wallstent (Boston scientific, USA) and Protégé (Medtronic, USA). Whereas, Roadsaver (Terumo Corp, Tokyo, Japan) was used in 1 case. Theoretically, having a stent with relatively narrow mesh may reduce the showering of emboli through the struts of the stent and reduce the peri-procedural risk of stroke. This theory has to be proven by randomized trials comparing different types of stents.

The limitations of our study included its nonrandomized type, the absence of control group, in addition to the lack of long term follow.

\section{Conclusion:}

Carotid artery angioplasty/stenting is an effective and safe alternative to carotid endarterectomy. Further studies assessing the value of embolic protective devices and the best type of stent are needed.

\section{References}

1- BONATI L.: Stenting or endarterectomy for patients with symptomatic carotid stenosis. Neurol. Clin., 33: 459-74, 2015.

2- WHITE H., BODEN-ALBALA B., WANG C., et al.: Ischemic Stroke Subtype Incidence Among Whites, Blacks, and Hispanics: The Northern Manhattan Study. Circulation, 111: 1327-31, 2005.

3- FERGUSON G., ELIASZIW M., BARR H., et al.: The North American Symptomatic Carotid Endarterectomy Trial Surgical Results in 1415 Patients. Stroke, 30: 17518, 1999.

4- European Carotid Surgery Trialists' Collaborative Group. Randomised trial of endarterectomy for recently symptomatic carotid stenosis: final results of the MRC European Carotid Surgery Trial (ECST). Lancet, 351: 1379-87, 1998.

5- MORR S., LIN N. and SIDDIQUI A.: Carotid artery stenting: Current and emerging options. Medical Devices: Evidence and Research, 7: 343-55, 2014.

6- BROTT T., HALPERIN J., ABBARA S., et al.: Guideline on the management of patients with extracranial carotid and vertebral artery disease: Executive summary. Stroke, 42: e420-e463, 2011.

7- BONATI L., DOBSON J., FEATHERSTONE R., et al. Long-term outcomes after stenting versus endarterectomy for treatment of symptomatic carotid stenosis: The International Carotid Stenting Study (ICSS) randomised trial. Lancet, 385: 529-38, 2015. 
8- YADAV J., WHOLEY M., KUNTZ R., et al.: Protected Carotid-Artery Stenting versus Endarterectomy in HighRisk Patients. N. Engl. J. Med., 351: 1493-501, 2004.

9- The SPACE Collaborative Group. 30 day results from the SPACE trial of stent-protected angioplasty versus carotid endarterectomy in symptomatic patients: A randomised non-inferiority trial. Lancet, 368: 1239-47, 2006.

10- MAS J., CHATELLIER G., BEYSSEN B., et al.: Endarterectomy versus Stenting in Patients with Symptomatic Severe Carotid Stenosis. N. Engl. J. Med., 355: 1660-71, 2006.

11-International Carotid Stenting Study investigators. Carotid artery stenting compared with endarterectomy in patients with symptomatic carotid stenosis (International Carotid Stenting Study): An interim analysis of a randomised controlled trial. Lancet, 375: 985-97, 2010.

12- BONATI L., DOBSON J., FEATHERSTONE R., et al.: Long-term outcomes after stenting versus endarterectomy for treatment of symptomatic carotid stenosis: The International Carotid Stenting Study (ICSS) randomised trial. Lancet, 385: 529-38, 2015.

13- BROTT T., HOBSON R., HOWARD G., et al.: Stenting versus Endarterectomy for Treatment of Carotid-Artery Stenosis. N. Engl. J. Med., 363: 11-23, 2010.

14- BROTT T., HOWARD G., ROUBIN G., et al.: Long-term results of stenting versus endarterectomy for carotidartery stenosis. N. Engl. J. Med., 374: 1021-31, 2016.

15- BONATI L., LYRER P., EDERLE J., et al.: Percutaneous transluminal balloon angioplasty and stenting for carotid artery stenosis. Cochrane Database Syst. Rev., Sep., 12; (9): CD000515, 2012.

16- Carotid Stenting Trialists' Collaboration. Short-term outcome after stenting versus endarterectomy for symptomatic carotid stenosis: A preplanned meta-analysis of individual patient data. Lancet, 376: 1062-73, 2010.
17- TEXAKALIDIS P., CHAITIDIS N., GIANNOPOULOS S., et al.: Carotid Revascularization in Older Adults: A Systematic Review and Meta-Analysis. World Neurosurg., Feb., 22. pii: S1878-8750 (19): 30441-3, 2019.

18- BROTT T., CALVET D., HOWARD G., et al.: Longterm outcomes of stenting and endarterectomy for symptomatic carotid stenosis: A preplanned pooled analysis of individual patient data. Lancet. Neurol. Apr., 18 (4): 34856, 2019.

19-HARTOG A., ACHTERBERG S., MOLL F., et al.: Asymptomatic carotid artery stenosis and the risk of ischemic stroke according to subtype in patients with clinical manifest arterial disease. Stroke, 44: 1002-7, 2013.

20- NAYLOR A., GAINES P. and ROTHWELL P.: Who benefits most from intervention for asymptomatic carotid stenosis: Patients or professionals? Eur. J. Vasc. Endovasc. Surg., 37: 625-32, 2009.

21- WALKER M., MARLER J., GOLDSTEIN M., et al.: Endarterectomy for Asymptomatic Carotid Artery Stenosis. JAMA, 273 (18): 1421-8, 1995.

22- HALLIDAY A., HARRISON M., HAYTER E., et al.: 10year stroke prevention after successful carotid endarterectomy for asymptomatic stenosis (ACST-1): A multicentre randomised trial. Lancet, 376: 1074-84, 2010.

23- ROSENFIELD K., MATSUMURA J., CHATURVEDI S., et al.: Randomized trial of stent versus surgery for asymptomatic carotid stenosis. N. Engl. J. Med., 374: 1011-20, 2016.

24- YANG C., BOGIATZI C. and SPENCE D.: Risk of stroke at the time of carotid occlusion. JAMA Neurol., 72 (11): 1261-7, 2015

25- MOTT M., KOROSHETZ W. and WRIGHT C.: CREST2: Identifying the Best Method of Stroke Prevention for Carotid Artery Stenosis. Stroke, 48: e130-e131, 2017. 


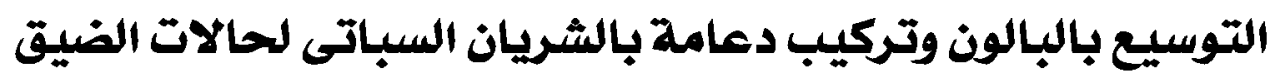

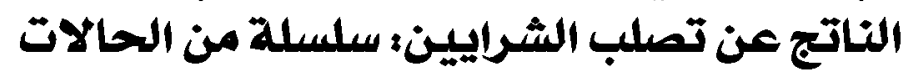

السكتات الدماغية هي ثالث آسباب الوفاة عالمياً قآول آسباب حدوث إعاقة جسدية دائمة. تشكل السكتات الدماغية الناتجة عن ضيق الشريان السباتى بالرتبة بسبب ترسبات تصلب الثرايين ما يقرب من ـ ا-هاء من آسباب السكتات الدماغية.

آثبتت الآبحاث العلمية آن إجراء جراحة لإستئصال ترسبات بطانة الشريان المتصلب توفر درجة آمان آفضل من العلاج الدوائى في حالات الضيق الصاد بالشريان السباتى.

كما آثبتت الابحاث الدولى كذلك آن إجراء توبسيع بالبالون وتركيب دعامة بالشريان السباتى فى حالات الضيق الهاد توفر درجة آمان آعلى من العلاج الدوائى.

تباينت نتائج الآبحاث الدولية فيما يتعلق بالمقارنة ما بين الجراحة وتركيب الدعامة فيما يتملق بنسب النجاح ودرجة خطودة كل إجراء.

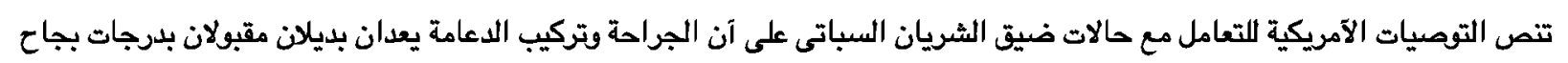
وآمان متقارية وآن المريض له الحق في الإختيار ما بين الإجرائين العلاجيين.

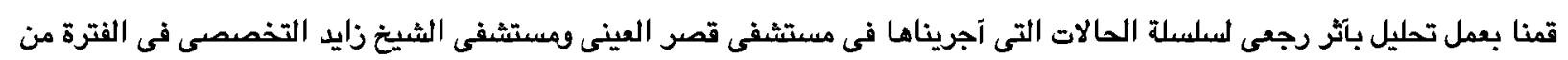

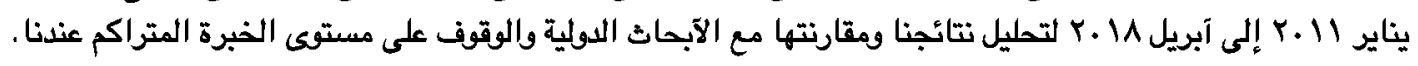
آظهرت الدراسة آن نتائجنا فى توبسع الشريان السباتى وتركيب دعامة تنسق مع النتائج الدولية وتوفر درجة آمان مناسبة للمرضي. 